\title{
Research on Control System of Food Processing Testing Machine
}

\author{
Bin Zhang ${ }^{1, *}$, Qinghui Yuan ${ }^{1}$ and Guofang Feng ${ }^{2}$ \\ ${ }^{1}$ Binzhou Polytechnic, Binzhou, Shandong Province256603, China \\ ${ }^{2}$ Sixth Primary Schools in Bincheng, Binzhou, Shandong Province, China \\ *Corresponding author.Email: 183156237@qq.com
}

\begin{abstract}
This article introduced one kind of brand-new control system about food processing, which uses on the lower and upper position machine structure pattern, by the plate computer machine took on the upper position machine, and SCM takes on the lower position machine. Paper main content covers system design, hardware and software design as well as upper position machine application software design.
\end{abstract}

Keywords: food processing, PID control, configuration software

\section{INTRODUCTION}

Food processing industry is not only the life industry of human beings, but also an everlasting industry. China's food processing automation industry started relatively late, and ruiran developed rapidly. However, most of the food industry enterprises are small-scale, backward equipment, low technology content of equipment, the automatic control system is out of touch with the process design and mechanical manufacturing, the product performance stability is not good, the complete set is poor, and the precision and automation degree are low. When introducing foreign advanced equipment, the digestion and absorption and independent innovation are not enough, the investment in technology development is small, the product lacks characteristics, the product structure is unreasonable and the adjustment is slow; There are few large-scale equipment with high technology content, many with low added value and low level, and there is a big gap between the stability and durability of equipment and international advanced products; High precision food processing and packaging machinery and parts are still heavily dependent on imports, which are not suitable for the rapid development of China's food industry. Therefore, with the popularization and application of microcomputer, it is of great practical significance to improve the level of food processing automation in China and to realize microcomputer system control.

\section{WORKFLOW OF FOOD PROCESSING EXPERIMENTAL MACHINE}

The workflow is as follows:

(1) Preheating: when the 1, 2 and 3 heaters on the barrel are powered on, they will stop automatically until the temperature of the equipment is reduced, and then they will be heated automatically.
(2) Start up: the oil pump is on, and the main engine is on after 1-2 minutes.

(3) Turn on the main motor, turn on the feeding motor, and add 150 cubic centimeters of water at the same time.

(4) After 3-5 minutes, the head is discharged normally, and the speed of the main motor feeding motor is raised to a certain set value.

(5) If the heater 1, 2 and 3 overheats and exceeds the set value by 3 degrees during operation, the cooling pump will automatically stop when it starts to cool to the predetermined cooling time.

(6) After the normal discharge of the head, set the appropriate speed of the rotary cutting motor, and the rotary cutting device cuts off the discharge.

(7) At the end of the work, first reduce the speed of the feeding motor, then reduce the speed of the main motor, and then stop the machine.

\section{CONTROL SYSTEM FUNCTION AND MAIN TECHNICAL INDEX}

Process control of control system. Main technical specifications:

(1) Speed regulation range of main motor: $0 \sim 1440 \mathrm{r} / \mathrm{min}$

(2) Feeding motor speed range: $0 \sim 1400 \mathrm{r} / \mathrm{min}$

(3) Speed range of rotary cutting motor: $0 \sim 1400 \mathrm{r} / \mathrm{min}$

(4) Temperature regulation range of heating cylinder:50 550 $\bigcirc \mathrm{C}$

(5) Head pressure measurement $<30 \mathrm{MPa}$

(6) Lubrication system pressure measurement $<0.2 \mathrm{MPa}$

(7) Animation shows the working process of the machine

(8) When the speed, temperature and pressure are abnormal, alarm and switch are realized

(9) The working condition of the machine is monitored in real time, and the fault alarm and fault backward safe conversion are realized

(10) Real time display of experimental parameters, display and modify the experimental table data on CRT, reserve 
the printing port, and print out the experimental table when necessary.

(11) The manual and automatic switching is realized, the process flow is intervened manually, and the control parameters are input online.

\section{OVERALL CONTROL SCHEME DESIGN OF 3 FOOD PROCESSING TESTING MACHINE SYSTEM}

DCS (distributed control) system and RS-485 fieldbus are adopted.

\section{- 4.1. Ppc-1501 industrial PC is adopted as the main machine, which undertakes the following tasks}

(1) The interface is composed of human-machine, which realizes the input of command and parameters, and realizes the output of experimental tables, curves and alarm information.

(2) Control input module, collect information of various working conditions.

(3) The control algorithm is realized, and the time optimal

PID algorithm is used to control the temperature.

(4) According to the process logic output control.

(5) Judge the abnormal situation, realize the safe conversion of fault, and send out the alarm signal.

\section{- 4.2. Brief introduction of input and output module}

The input and output module is based on the design of single chip microcomputer. It exchanges information with the host computer through RS-485 bus to realize the parameter collection of temperature, pressure, lubrication, cooling and other components, receive the command and output control quantity of the host computer, and realize the control of the process flow.

\section{- 4.3. Frequency control equipment}

The frequency conversion and speed regulation equipment adopts Siemens frequency conversion speed regulator, which outputs constant torque, communicates with the host through RS-485 bus, receives speed regulation command, and outputs set speed.

\section{SOFTWARE AND HARDWARE DESIGN OF THE LOWER COMPUTER IN THE CONTROL SYSTEM OF THE TESTING MACHINE}

\section{- 5.1. Design of temperature control module}

Using PT100 thermal resistance sensor as the temperature measuring device and AT89C52 as the control core, a single-chip microcomputer control system is constructed to control the external heating equipment, and the accurate control of temperature is realized through the algorithm. Hardware circuit function: the signal is filtered, amplified, quantized and sent to the MCU, and then output control peripherals. At the same time, it can be controlled and displayed on the microcomputer or by the keyboard. The system schematic diagram is as follows:

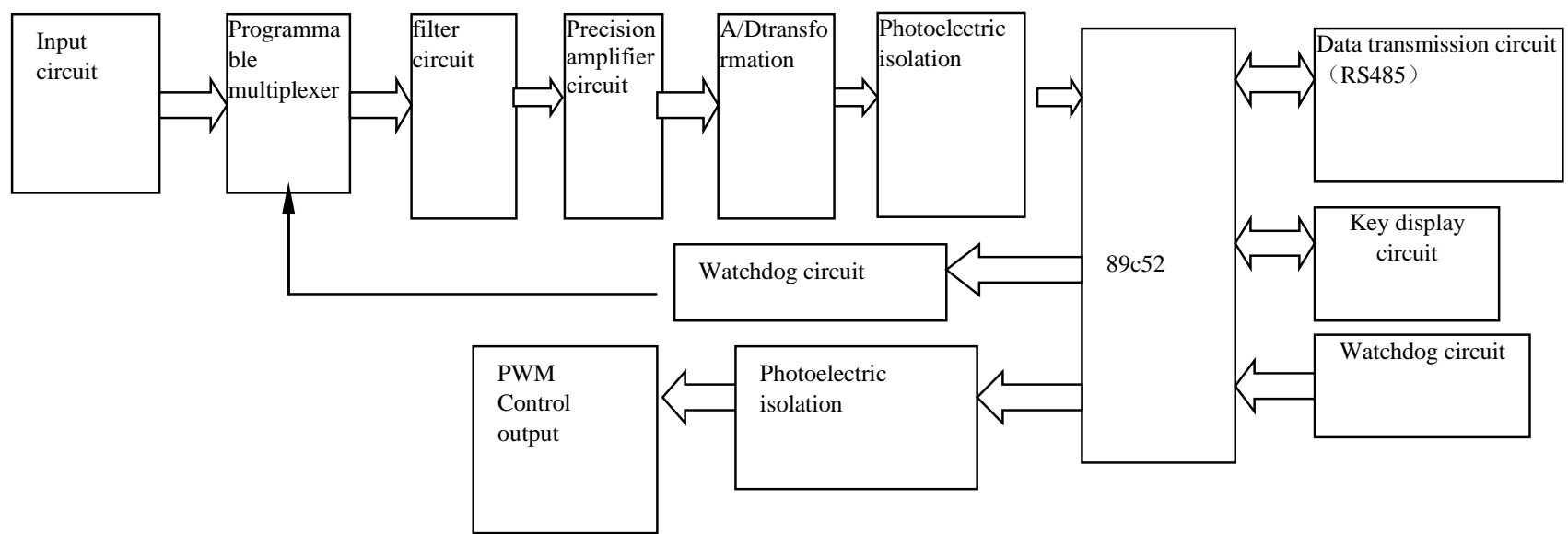

Figure 1 System principle block diagram 


\section{- $\quad 5.2$ Switch input and output module}

This paper designs a low-cost, high-performance multi-channel switch input and output module based on MCU and shift register. The 89C52 of ATMEL company is used as the microprocessor. Because there are relatively few I / O ports, it is necessary to expand the MCU interface. The serial shift register $74 \mathrm{hc} 165$ is used to expand the parallel port to input the switch state, and the serial parallel conversion chip $74 \mathrm{HC} 164$ is used to output the control signal, which can detect 32 channels of switch state and control 32 channels of output. In this way, the design only needs six port lines of single chip microcomputer AT89C52, and the expansion interface is reserved.

The hardware part mainly includes MCU, parallel input and output interface expansion circuit, input and output channel circuit, key display circuit, data communication circuit, watchdog circuit, etc., as shown in Figure 2.

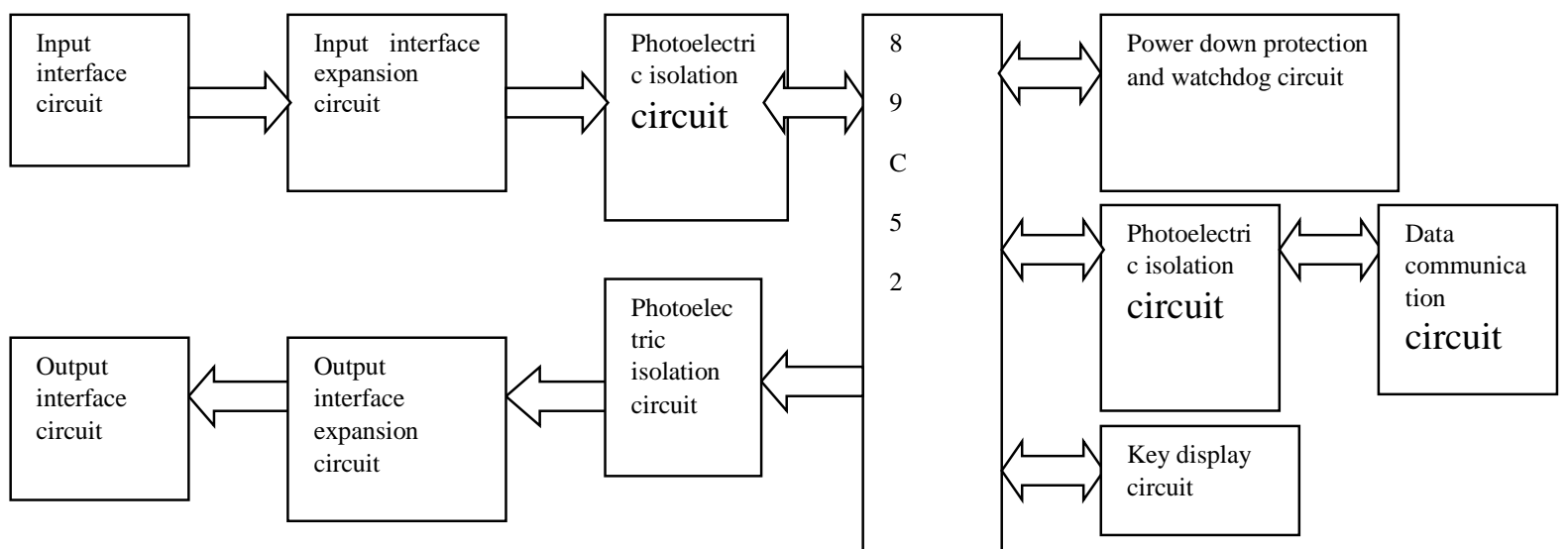

Figure 2 Principle block diagram

\section{- $\quad 5.3$ Lower computer software}

The detection and control function of the system is completed by the lower computer, so the lower computer software is the main part of the system software. The control system uses assembly language for programming. Because the program is large, it uses modular structure, through subroutine call, hierarchical, including communication with the upper computer, input acquisition, controlled quantity control, etc.

\section{DESIGN OF UPPER COMPUTER SOFTWARE FOR FOOD PROCESSING TEST MACHINE}

\section{- $\quad 6.1$ Realization of system control level}

The reliability of system control level is an important indicator of the performance of the whole system, so the design of system control level is very important.

\subsubsection{Automatic / manual operation mode}

The whole control system is divided into automatic operation mode and manual working mode. The automatic working mode is that all the actions of the whole system are completed automatically, that is, it is controlled by the computer. The automatic part includes the start and stop of main motor, feed motor and rotary cutting motor, the start and stop of three heaters, the start and stop of three cooling pumps and the start and stop of water injection valve. Manual operation mode is mainly used when the system is

debugged or the system fails. The automatic working mode and manual working mode can realize the undisturbed switching. When the system fails, it can be converted to manual mode for timely processing. After processing, it can ensure the continuous operation in the automatic working mode, which greatly improves the operability of the system.

\subsubsection{Manual programming and automatic programming}

The manual program and automatic program design are realized by the command language of Kingview event, which mainly includes start and stop events, automatic manual operation events, motor start and stop events, heater start and stop times, start and stop events of cooling pump, start and stop time of lubricating pump, and start and stop events of water injection valve.

\section{- $\quad 6.2$ Design of control software for upper computer}

The upper computer software includes the input of control parameters, the display of controlled quantity, the realization of PID control algorithm, the communication 
with the lower computer, the VB program design and so on.

\subsubsection{Input of control parameters and display of controlled quantity}

The biggest advantage of this design is to form a visual man-machine interface combined with the powerful graphic function of the microcomputer. For some control parameters of the lower computer, the hardware of the lower computer can produce corresponding actions by clicking and inputting on the screen of the upper computer, and the value of the controlled quantity can also be displayed graphically on the screen of the upper computer.

\subsubsection{PID control algorithm}

For temperature control, the upper computer adopts VB to realize the time optimal PID control method, and transmits the control quantity to the lower computer through serial port, while the lower computer transmits the collected temperature value to the upper computer as the input of the control system.

\section{- $\quad$ 6.3 Design of monitor screen based on Kingview}

\subsubsection{Parameter setting}

The parameter setting is the default of the system, and the operator can modify the above parameters according to the actual situation and work experience.

\subsubsection{Operation}

The operation screen can monitor the operation of the field equipment in real time. From the information displayed on the operation screen, we can see whether the equipment is running normally. This screen can view the running speed of the motor, the real-time temperature value, pressure value and other parameters of the barrel. It can also change its setting value through the text box, and start and stop the various equipment of the testing machine system.

\subsubsection{Historical curve}

For the temperature, pressure and other important parameters in the barrel, the trend curve is generally used to show. Through the historical trend curve, we can get the past time and data. When the software is running, the historical trend curve will not automatically scroll, it generally works with the function button.

\subsubsection{Real time curve}

Real time trend curve is used to display the change of data in real time. The real-time trend curve is automatically updated by the system, the data enters from the right side of the window, and the trend moves from right to left, respectively displaying the real-time changes of three important parameters: temperature, pressure and speed.

\subsubsection{Alarm window}

Alarm means that when the value of some quantity in the system exceeds the specified limit, the system will automatically generate corresponding warning information In this system, if the temperature, pressure and motor rotation of the testing machine exceed the upper limit or lower than the lower limit, an alarm will be generated to prompt the operator to pay attention.

\section{CONCLUSION}

In this study, the improved PID algorithm is used to control the temperature. In the control process, the structure and coefficient are changed, and the empirical algorithm is integrated into it. The effect is excellent. Compared with the domestic high-end food processing test machine, the performance index is significantly improved. In addition, this paper also solves the interface problems of various software and hardware platforms, and solves the problems of reliability, maintainability and electromagnetic compatibility in the research and design.

\section{REFERENCES}

[1] Zhang Yi. Computer control technology [M]. Beijing: China Machine Press, 2004

[2] Tong Shibai. Fundamentals of analog electronic technology [M]. Beijing: Higher Education Press, 2001

[3] Jing Yanbo. Microcomputer control system of food processing testing machine $[\mathrm{J}]$. Automation technology and application, 2007 (8): 108-110

[4] $\mathrm{Wu}$ Youqing. Application of proportioning control system in feed processing industry $[\mathrm{J}]$. Grain and feed, 1998 (9): 32-34

[5] Cao Weifang. Research on general control module based on MCS-51 series single chip microcomputer [D]. Shandong University of science and technology, 2005:32-56

[6] J. He, X. Liu,et al. High Annealing Stability of InAlZnO Nanofiber Field-Effect Transistors with Improved Morphology by Al Doping. Journal of Physical Chemistry Letters, 12.4(2021)1339-1345.

[7] H. Zu, Y. Chang, H. Li, et. al., Modulating the Transport Properties of Metal Oxide Nanofibers Transistors by Controlling the Grain Size. IEEE Electron Device Letters. 42.6(2021)855-858. 
[8] D. Liu, B. Yu, M. Liao, et. al.,Self-Powered and Broadband Lead-Free Inorganic Perovskite Photodetector with High Stability, ACS Applied Materials \& Interfaces, 12.27(2020)30530-30537.

[9] H. Li, P. Xu, et. al., Low-voltage and fast-response $\mathrm{SnO} 2$ nanotubes/perovskite heterostructure photodetector, Nanotechnology, 32(2021)375202.

\section{Author introduction}

Zhang Bin, male, Binzhou Shandong, Binzhou Polytechnic, mainly engaged in electrical automation engineering research and management. 